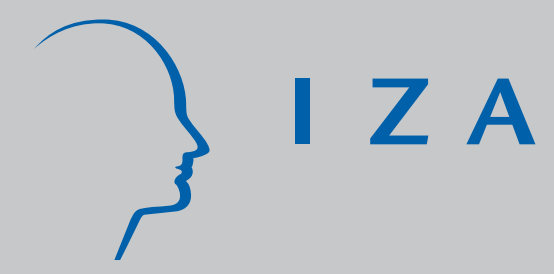

IZADP No. 1513

Estimating the Effect of a Retraining Program for Displaced Workers on Their Transition to Permanent J obs

Sandra Cavaco

Denis Fougère

J ulien Pouget

March 2005 


\title{
Estimating the Effect of a Retraining Program for Displaced Workers on Their Transition to Permanent Jobs
}

\author{
Sandra Cavaco \\ Aarhus School of Business \\ and GATE, Université Lyon 2 \\ Denis Fougère \\ CNRS, CREST-INSEE, \\ CEPR and IZA Bonn \\ Julien Pouget \\ CNRS, CREST-INSEE \\ and IZA Bonn
}
Discussion Paper No. 1513
March 2005

\author{
IZA \\ P.O. Box 7240 \\ 53072 Bonn \\ Germany \\ Phone: +49-228-3894-0 \\ Fax: +49-228-3894-180 \\ Email: iza@iza.org
}

\begin{abstract}
Any opinions expressed here are those of the author(s) and not those of the institute. Research disseminated by IZA may include views on policy, but the institute itself takes no institutional policy positions.

The Institute for the Study of Labor (IZA) in Bonn is a local and virtual international research center and a place of communication between science, politics and business. IZA is an independent nonprofit company supported by Deutsche Post World Net. The center is associated with the University of Bonn and offers a stimulating research environment through its research networks, research support, and visitors and doctoral programs. IZA engages in (i) original and internationally competitive research in all fields of labor economics, (ii) development of policy concepts, and (iii) dissemination of research results and concepts to the interested public.
\end{abstract}

IZA Discussion Papers often represent preliminary work and are circulated to encourage discussion. Citation of such a paper should account for its provisional character. A revised version may be available directly from the author. 


\begin{abstract}

\section{Estimating the Effect of a Retraining Program for Displaced Workers on Their Transition to Permanent Jobs}

In this paper we estimate the short-term effects of a French retraining program that was intended to improve reemployment prospects of displaced workers. Our empirical analysis uses non-experimental data collected by the French Ministry of Labour. Transitions from unemployment to permanent vs. temporary jobs are assumed to be generated by a dependent competing risks duration model. Moreover we assume that program entry but also direct transitions from the program to employment are both affected by a selectivity process depending on observable and unobservable individual heterogeneity. We find mixed evidence regarding relevance of the program. For displaced workers who join the program, program participation increases the average probability to obtain a permanent job by 8 points (passing from 42 to $50 \%$ ). However, for displaced workers who do not join the program, this average probability would have been increased by 28 points (passing from 43 to $71 \%$ ) had they participated in the program. We conclude that, although the program has been globally effective, it has been insufficiently proposed to the displaced workers who would have benefited the most from it.
\end{abstract}

JEL Classification: $\quad \mathrm{C} 41, \mathrm{~J} 24, \mathrm{~J} 64, \mathrm{~J} 68$

Keywords: evaluation, re-employment program, displaced workers, unemployment duration, dependent competing risks model

Corresponding author:

Denis Fougère

CREST-INSEE,

15 Boulevard Gabriel Peri

92245 Malakoff Cedex

France

Email: fougere@ensae.fr 


\section{Introduction}

Improving the effectiveness of active labour market programs (ALMPs) is a main policy area identified by the OECD Jobs Strategy for helping to reduce structural unemployment (OECD, 1994 and 1996). In an era of tight government budgets and a growing disbelief regarding the positive effects of ALMPs, evaluation of these programs becomes imperative. ${ }^{1}$ On the one hand, the persistently high level of unemployment rates stresses the necessity of assistance programs in helping unemployed participants to find a job faster. On the other, it is often doubted whether the positive effects of active programs outweigh their costs. Moreover, advocates of a pessimistic perspective even argue that participation in such programs in periods of high unemployment may be seen as a negative signal for some employers and could therefore have a counter-productive impact on the employment performance of participants.

Active labour market policies have been increasingly introduced in France since the midseventies, when unemployment started to increase. These policies were targeted to workers with high unemployment risks, such as young people, older or displaced workers. They are similar to those implemented in other European countries, France being a median user. In France, the scope of public interventions is rather diversified. Most of the programs consist in providing training, job seeking support, vocational course, and adaptation training (for the youngest). Some microeconometric studies carried out by Bonnal, Fougère and Sérandon (1997), Fougère, Kramarz and Magnac (2000), and Brodaty, Crépon and Fougère (2001) have investigated the impact of such policies on employment prospects of young people and unskilled workers. However, few contributions have addressed the issue of employment programs for laid off or displaced workers ${ }^{2}$.

Worker displacement involves an involuntarily job separation caused by adverse economic conditions. In such a case, the job separation is initiated by the employer and not caused by the individual worker's performance. In general displaced workers are more likely to

\footnotetext{
${ }^{1}$ An updated summary of both empirical strategies and evidence on the effects of ALMPs can be found in Heckman et al. (2000). In general, these studies find mixed evidence regarding the relevance of programs on both unemployment duration and earnings of participants.

${ }^{2}$ Margolis (1999) is an exception since he examines the impact of displacement on unemployment duration in France. However he does not evaluate the effect of active labour market programs proposed to displaced workers.
} 
experience longer unemployment spells and to incur higher search costs, including possibly costs involved by retraining and moving to areas with higher employment opportunities.

Displaced workers have been the subject of an extensive literature (see surveys by Fallick, 1996, and Kletzer, 1998). The basic stylised facts are: 1) displaced workers experience longer unemployment spells and higher earning losses than the other unemployed workers (Swaim and Podgursky, 1991, Jacobson, Lalonde and Sullivan, 1993); 2) the duration of the subsequent unemployment spell increases with job tenure (Fallick, 1996), because workers with high tenure have a higher level of specific human capital investment in their firms and in their industry or occupational sectors; 3 ) the duration of this unemployment spell is affected by the cause of displacement; for instance, Swaim and Podgursky (1991) found that workers displaced because of plant closures experience one third fewer weeks of unemployment than those who are laid off by ongoing establishments. The econometric analysis conducted by Gibbons and Katz (1991) has shown that this result could not be attributed solely to differences in observable worker characteristics. These authors argued that it is due to a "lemon" effect: prospective employers perceive laid off workers as being of low ability compared to people who lose their job due to plant closure.

In view of the difficulties the displaced workers face in achieving reinsertion, debates arise on the suitable policies to be undertaken. As there is little prospect of returning to a comparable job within a reasonable period of time (because of limited opportunities in the same industry, occupation or region), displaced workers may need retraining or search assistance. While retraining of displaced workers is not a new policy, programs to assist displaced workers have gained a renewed interest. In general, such programs offer job search assistance along with formal training. In his landmark study on displaced workers, Leigh (1990) concludes that job search assistance is the most cost-effective program for displaced workers. It also appears that training can shorten the periods of unemployment, but it does not affect long-term earnings. Leigh (1990) synthesizes some findings from his examination of labour market policies in Sweden, Germany, Japan, Great Britain and Australia. The main results are the following: job search assistance is relatively cheap and should be made freely available to those recommended by their case managers; quality assessment should be conducted for those wishing to join a retraining program; training should be locally based and characterized by decentralized decision-making to meet local needs more appropriately. Dar and Gill (1998), after studying eleven retraining programs in six countries, concluded that such programs are 
generally no more effective than job search assistance in increasing re-employment prospects. As a result, they should be targeted to those who can benefit the most from them : women and minorities (Moore, 1990), industry-switchers (Stock, 1998), laid off workers from manufacturing (Kletzer, 1998), or those with high tenure (Jacobson et al., 1993). In fact job search assistance and training appear to have some impact on the types of jobs that displaced workers obtain. Farber $(1999,2003)$ found that workers who lose their jobs are more likely to be reemployed in temporary jobs and, when reemployed in a permanent job, they earn significantly less than they did prior to their last job. Thus an obvious important consequence of job loss is the inability to find a new stable job. ${ }^{3}$

Our study concerns a retraining program, called "Convention de conversion", which was set up in France during the eighties in order to improve labour market prospects of displaced workers. It consists in providing an immediate and individual support to displaced workers for a period of six months (beginning just after the dismissal) by proposing retraining and job seeking assistance. This support is granted to workers up to 57 years old who have at least two years of seniority in their former firm. US training programs mainly focus on increasing the productivity and earnings of low-income individuals. In contrast, the main purpose of this French program is to prevent or to reduce unemployment by increasing the participants' employment rates rather than their earnings. Thus our study boils down to the following question: do program participants manage to find a permanent job faster? Hence, the outcomes of interest are both the unemployment duration and the probability to find a longterm labour contract.

Our empirical analysis uses non-experimental data collected by the French Ministry of Labour from 1995 to1998. A first survey, called "Trajectoires des demandeurs d'emploi et marché local du travail" ("Event histories of unemployed workers and local labour markets") has collected information on workers who entered unemployment between April and June 1995 in eight local labour markets belonging to three administrative regions: Paris - Ile de France, Nord - Pas de Calais, and Provence - Alpes Côte d'Azur. This survey has been completed by another one, called "Trajectoires des adhérents à une convention de conversion" ("Event histories of displaced workers participating to the 'Convention de conversion' program").

\footnotetext{
${ }^{3}$ In 2003 in France, one year after their displacement, only $15 \%$ of laid off workers have found a new permanent job, $15 \%$ are occupied in temporary jobs, $10 \%$ are in training programs or pre-retired, and $60 \%$ are still unemployed.
} 
This second survey was conducted in the same local areas with the same questionnaire, but exclusively on displaced workers joining the program during the same initial period.

The major challenge of any evaluation study using non-experimental data is to treat the potential selection bias. Displaced workers who have decided to join the program might have unobserved characteristics that would be different from those who have not joined it. Workers participating in such a program may be less or more able to find a permanent job (namely, a job with a long-term labour contract) compared to otherwise identical non-participants. The difference in post-program outcomes between participants and the control group of nonparticipants may reflect unobserved factors rather than a causal effect of the program. To estimate the effect of the retraining program on the transition to permanent jobs, we propose an extended version of the switching regression model frequently used in econometric evaluation studies. More precisely, our simultaneous equations model takes into account two possible sequential endogenous selection processes: the first one corresponds to the selection at entry in the program, the second one corresponds to a possible selection affecting direct transitions from the program to employment, without experiencing any intermediate unemployment spell. Transitions from unemployment either to permanent jobs or to temporary jobs ${ }^{4}$ are then formalized through a dependent competing risks duration model. This model takes into account right-censored unemployment durations.

The paper is organized as follows. In the second section, we give a brief summary of the French institutional framework concerning layoffs, and then we present the main specific features of the retraining program that we evaluate. The third section presents the database. The fourth section develops the econometric model. A fifth section presents and comments the estimates. The sixth section summarizes the main results.

\footnotetext{
${ }^{4}$ In our study, temporary jobs include fixed-term contracts, interim or subsidized jobs. The limited size of our sample prevents us to do a more precise analysis by distinguishing other categories such as full-time jobs versus part-time jobs. The distinction between permanent jobs versus temporary jobs appears to be relevant in order to examine the average quality of the corresponding jobs. For instance, in 1996, which is the median year of our survey, the average net monthly wage of workers occupied in permanent jobs was equal to 10,170 French francs, and $87 \%$ among them worked full-time; the same year, the average net monthly wage of workers occupied in temporary jobs was equal to 6,810 French francs, and $69 \%$ only were employed full-time (source: "Enquête sur l'emploi', INSEE, Paris, 1996).
} 


\section{The institutional framework}

French labour law distinguishes between layoffs for economic reasons and layoffs for personal reasons, such as inadequate performance or misconduct. A layoff for economic reason is defined as a displacement resulting from a reduction in the workload or a lost position or shift. During the 1990s the French labour market was characterized by numerous job losses; for instance, each month in 1998, on average 25000 employees were laid off. One common characteristic of all layoffs for economic reasons is that employers are required to propose the option of participating in a retraining scheme (partially employer funded) to all employees who will be displaced. This clause became an actual right inscribed into the Labour code. The retraining program called "Convention de conversion" was introduced by a decree in date of $3^{\text {rd }}$ and $4^{\text {th }}$ April 1987 as a compensation for the administrative authorization to lay off. It was then cancelled in June 2001.

The employee joining the retraining program was made redundant but was not registered as being actually unemployed. The initial goal of this program was to avoid long unemployment spells for employees who were laid off for economic reasons. It consisted in providing an immediate and individual support to the displaced workers for a period of six months beginning just after the dismissal. What were the eligibility conditions? Participation was voluntarily, but support was granted to workers up to 57 years old, having at least 2 years of seniority in the firm. Technical Units of Reinsertion ("Unités techniques de reclassement") were in charge of accompanying and reinserting participants. They assessed the employee's professional records and then, proposed appropriate actions including job-seeking sessions, stressing self-employment opportunities, on-the-job assessment and extra training (computer, accounting, management, languages, etc...). The benefit of extra education and support in job seeking throughout the program was meant to reduce the subsequent unemployment spell and more generally to improve the conditions of reinsertion into the labour market. During the first two months of the program, the worker received a specific allowance representing $83 \%$ of his or her previous wage. This percentage fell down to $70 \%$ during the four following months.

Statistics published by the French Ministry of Labour show that, since 1997, the gap between the number of workers who joined the program and the number that is potentially entitled to join has been closing. Indeed, throughout the first semester of $1999,84.7 \%$ of the eligible 
workers joined it, while they were only $79.1 \%$ in 1996 (which was already a peak ${ }^{5}$ due to the important number of layoffs that year).

\section{The data}

The estimation is carried out using data coming from two surveys collected by French Ministry of Labour. The first one, called "Trajectoires des demandeurs d'emploi et marché local du travail", contains information on a random sample of workers entering unemployment between April and June 1995 in three French administrative regions (Paris-Ilede-France, Provence-Alpes-Côte d'Azur, and Nord-Pas-de-Calais). Indeed, these surveys are not representative of all the regions in France. These workers were interviewed at three dates, until May 1998. This first survey has been completed by another one, called "Trajectoires des adhérents à une convention de conversion", held in the same conditions and with similar questionnaires, but collected on workers joining the program at the same date. The originality of these surveys lies thus in the fact that individuals are randomly sampled in the inflows of displaced workers either joining the retraining program after dismissal or entering unemployment (without joining the program) during a given time interval. As a consequence, unemployment duration is not left censored.

To evaluate the causal effect of the program, one has to contrast the situation of individuals after program participation with the counterfactual situation in the absence of participation. Because the latter situation is not observable, it needs to be estimated, based on the outcome of other individuals who do not participate, the so called control group. When choosing or constructing this control group, different adjustment procedures may be applied to ensure that participants and controls are identical with respect to all relevant characteristics except that of not participating. In experimental evaluations, the construction of an adequate control group is done by means of randomisation. When non-experimental data are used, failure to take into account for discrepancies between participants and controls may lead to substantially biased judgements regarding the effect of the program. Here one has drawn the control group from the first survey in order to control for eligibility conditions at first stage. The control group is then only composed of individuals potentially entitled to join the program, which means that

\footnotetext{
${ }^{5}$ There were 148,492 new recipients of this program in 1996, which corresponds to an increase of $11.2 \%$ for the number of participants between 1995 and 1996.
} 
they respect the following imposed criteria used when applying to the program: they are under 57 years old, they are displaced and have at least two years of seniority in their previous firm. The whole sample, including both sub-samples (participants and non-participants), includes 1912 observations.

From a strict methodological point of view, we have to specify when the unemployment duration for a participant starts. After layoff, the employee is made redundant but he or she is not registered as an actual unemployed. Indeed, one may consider that program participation and unemployment both represent the same state of job seeking. However, the time spent in the program is principally devoted to training (see, for instance, Lalive et al., 2000). According to this remark, we consider time spent in the program and unemployment as two different states. Therefore, we do not include time spent in the program in the unemployment duration. This choice should not imply strong biases, since first our outcome variable is the probability to be hired in a new permanent job and not the unemployment duration per se, and second because we estimate simultaneously for participants the probability to move directly from the program to a permanent job and the probability to move from the subsequent unemployment spell (if any) to a permanent job.

Descriptive statistics for the two sub-samples (participants and non-participants) are displayed in Table 3, Appendix 1. The sub-sample of participants contains higher proportions of older workers with higher seniority (more than 10 years). Among the 1010 participants, 130 move directly from the program to a permanent job and 164 directly to a temporary job. The 716 remaining enter unemployment at the end of the program. Among these unemployed participants, 189 moved to a permanent job, 156 found a temporary job, the others 371 are either still unemployed at the end of the observation period, either in training or inactivity ${ }^{6}$. Among the 920 unemployed non-participants, 166 have found a permanent job and 236 a temporary labour contract. In fact, roughly $32 \%$ of participants have obtained a permanent job (either directly at the end of the program or after the unemployment spell following program participation). Conversely, only $18 \%$ of non-participants have moved from unemployment to a permanent job. It seems that participation in the program increases the frequency of

\footnotetext{
${ }^{6}$ As transitions to inactivity or training are not numerous, they are not treated as specific destinations in the dependent competing risks duration model. In other terms, unemployment spells ending with a transition towards inactivity or training are considered as right censored spells.
} 
transitions to regular (permanent) employment. The econometric model allows us to study this issue more precisely.

\section{The statistical model}

Evaluation methods usually try to compare two potential outcomes which are associated with two regimes, generally called "treatment" and "non-treatment". Identification assumptions as well as estimation methods have been extensively studied in this context. Usually the literature on evaluation distinguishes between a selection bias that may result from selection on observable covariates and/or from selection on unobservable heterogeneity. Our model is based on the assumption that both observable and unobservable characteristics affect the process of assignment to the program.

More precisely, our statistical model is a generalized Tobit model with multiple selectivity criteria (see, for instance, Maddala, 1983, p. 278-283). The variable $T_{0}$ represents the participation to the re-employment program. It is equal to 1 if the displaced worker wants to join the programs and if his or her application is accepted by the program's administrators. The variable $T_{0}$ is 0 otherwise. This variable is supposed to be generated by a latent index $T_{0}$ * that is a linear function of a covariate vector $Z_{0}$ and of an error tem $V_{0}$. Thus we have :

$$
T_{0}=\mathbf{1}\left(T_{0}^{*}>0\right)=\mathbf{1}\left(Z_{0} \theta_{0}+V_{0}>0\right)
$$

If $V_{0}$ is assumed to have a standard normal distribution $N(0,1)$, the probability that a displaced worker, with observable characteristics $Z_{0}$, joins the program is equal to $\Phi\left(Z_{0} \theta_{0}\right)$ where $\Phi$ is the cumulative univariate standard normal distribution.

Program participants may find a permanent job either directly at the end of the program or at the end of the unemployment spell following program participation. In order to take into account direct transitions at the end of the program, we introduce another dummy endogenous variable $T_{1}$, which is equal to 1 if the participant moves to a job directly at the end of the program and 0 otherwise. This variable is also supposed to be generated by a latent linear index, denoted $T_{1}$ :

$$
T_{l}=\mathbf{1}\left(T_{l}^{*}>0\right)=\mathbf{1}\left(Z_{l} \theta_{l}+V_{l}>0\right)
$$


Thus, under the assumption that $V_{l}$ is normally distributed, the probability that a displaced worker with observable characteristics $\left(Z_{0}, Z_{1}\right)$ joins the program and obtains directly a job at the end of the program, is equal to :

$$
\operatorname{Pr}\left(Z_{0} \theta_{0}+V_{0}>0, Z_{l} \theta_{l}+V_{l}>0\right)=\Phi_{2}\left(Z_{0} \theta_{0}, Z_{l} \theta_{l}, \rho_{l}\right)
$$

where $\Phi_{2}\left(a, b, \rho_{1}\right)$ is the cumulative bivariate standard normal distribution, with a correlation coefficient equal to $\rho_{l}$, and computed at the point $a=Z_{0} \theta_{0}, b=Z_{1} \theta_{1}$. The probability that this job is associated with a permanent (long-term) labour contract is specified as :

$$
T_{2}=\mathbf{1}\left(T_{2}^{*}>0\right)=\mathbf{1}\left(Z_{2} \theta_{2}+V_{2}>0\right)
$$

where $T_{2}$ is equal to 1 if the program participant moves into a permanent job directly at the end of the program and 0 if he or she moves directly to a temporary job. According to this sequential specification, the probability that a displaced worker joins the program and moves directly into a permanent job at the end of the program is :

$$
\operatorname{Pr}\left(Z_{0} \theta_{0}+V_{0}>0, Z_{l} \theta_{1}+V_{l}>0, Z_{2} \theta_{2}+V_{2}>0\right)
$$

We could have modelled transitions from the program to different labour states by using a multinomial Probit model with three simultaneous alternatives representing direct transitions to permanent jobs, direct transitions to temporary jobs, and transitions to unemployment, respectively. However this solution increases the number of latent variables and thus the number of correlation coefficients which should be estimated ${ }^{7}$.

In our application, we consider two types of transitions from unemployment: transitions to permanent jobs and transitions to temporary jobs. The latent unemployment durations associated with these two types of transitions are represented by two random variables denoted $\left(Y_{11}, Y_{12}\right)$ or $\left(Y_{01}, Y_{02}\right)$ whether the displaced worker joins or not the program. Each of these variables is assumed to be generated by a log-linear regression model :

\footnotetext{
${ }^{7}$ This alternative specification can be estimated by a simulated maximum likelihood technique. In fact we tried to implement it, but the iterative procedure could not converge successfully.
} 


$$
\ln Y_{j k}=X_{j k} \beta_{j k}+U_{j k}, j=0,1, k=1,2
$$

where $X_{j k}$ is a covariate vector, $\beta_{j k}$ is a parameter vector associated with $X_{j k}$, and $U_{j k}$ is an error term which is assumed to be normally distributed with mean zero and variance $\sigma_{j k}{ }^{2}$.

As the residuals $U_{j 1}$ and $U_{j 2}(j=0,1)$ are supposed to be correlated, the model corresponds to a dependent competing risks duration model. ${ }^{9}$ The events generated by the whole model, which is a model with seven simultaneous equations, are represented in Figure 1.

Figure 1 shows that only some endogenous variables of the model can be observed. For instance, if a displaced worker moves directly to a permanent job at the end of the program, only the endogenous dichotomous variables $\left(T_{0}, T_{1}, T_{2}\right)$ are observed. For a participant who enters unemployment at the end of the program and moves then to a temporary job, the observed variables are $\left(T_{0}, T_{1}, Y_{12}\right)$. Finally, if a displaced worker has not joined the program but is still unemployed at the end of the observation period, only the variable $T_{0}$ is observed.

\footnotetext{
${ }^{8}$ The covariate vector $X_{0 k}$ affecting the logarithm of the unemployment duration associated with a transition of type $k$ for a non-participant can be different from the covariate vector $X_{l k}$ which influences the logarithm of the unemployment duration associated with a transition of type $k$ for the same individual if he had participated.

${ }^{9}$ Our log-normal duration model is an accelerated hazard model, and not a proportional hazard model (see Lancaster, 1990, Florens, Fougère and Mouchard, 1996). In this model, the dependence between the latent duration associated with different transitions comes from their correlation coefficient. In hazard proportional models, this dependence is generally a consequence from the presence of correlated unobservable heterogeneity components, which affect proportionally the marginal hazard functions of latent durations.
} 
Figure 1. The model

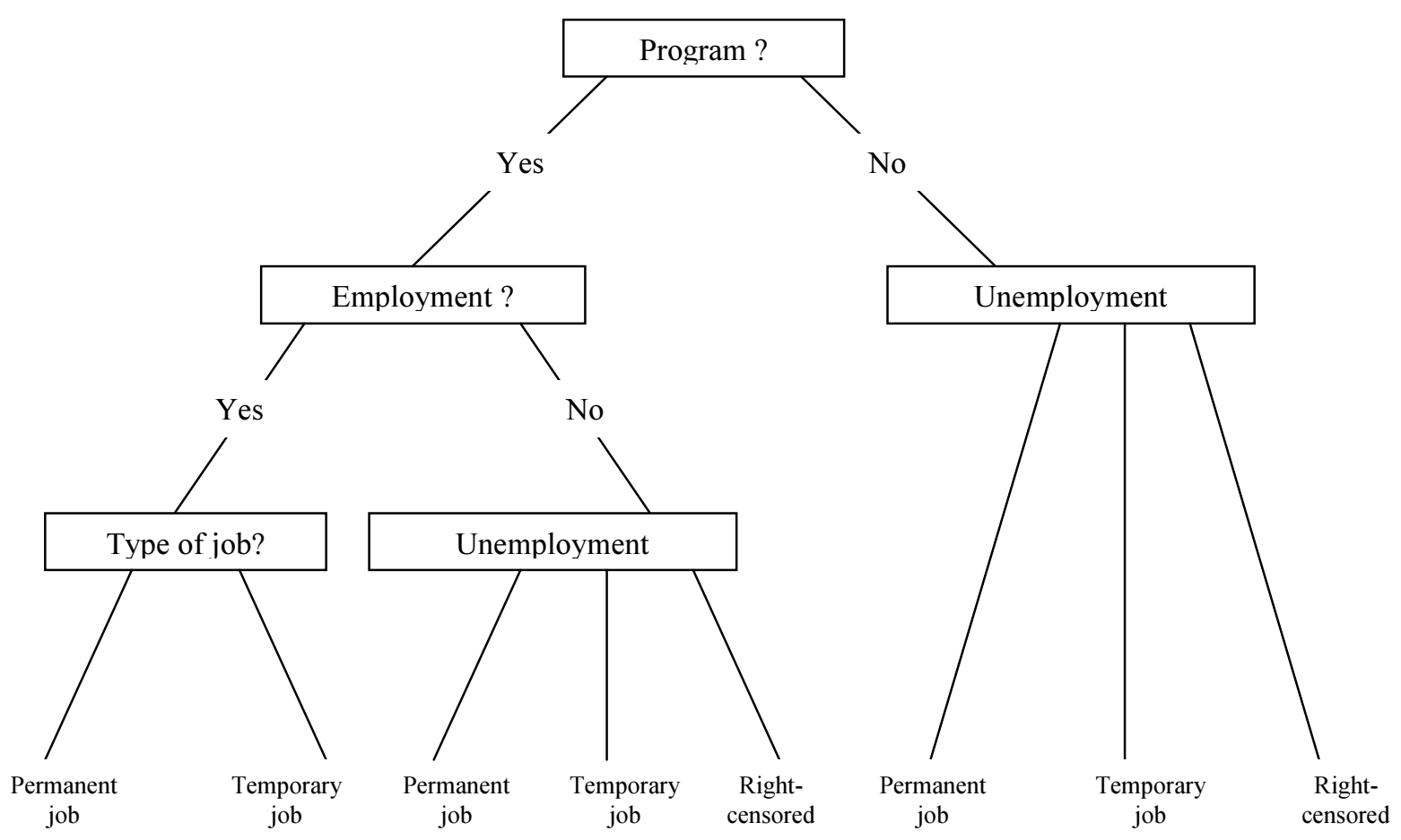

Residuals are supposed to be normally distributed with mean 0 and covariance matrix defined by:

$$
\left(\begin{array}{c}
V_{0} \\
V_{1} \\
V_{2} \\
U_{01} \\
U_{02} \\
U_{11} \\
U_{12}
\end{array}\right) \sim N\left(\left(\begin{array}{l}
0 \\
0 \\
0 \\
0 \\
0 \\
0 \\
0
\end{array}\right),\left(\begin{array}{ccccccc}
1 & 0 & \rho_{1} & \rho_{2} \sigma_{01} & \rho_{3} \sigma_{02} & \rho_{5} \sigma_{11} & \rho_{6} \sigma_{12} \\
0 & 1 & 0 & 0 & 0 & \rho_{8} \sigma_{11} & \rho_{9} \sigma_{12} \\
\rho_{1} & 0 & 1 & 0 & 0 & 0 & 0 \\
\rho_{2} \sigma_{01} & 0 & 0 & \sigma_{01}^{2} & \rho_{4} \sigma_{01} \sigma_{02} & 0 & 0 \\
\rho_{3} \sigma_{02} & 0 & 0 & \rho_{4} \sigma_{01} \sigma_{02} & \sigma_{02}^{2} & 0 & 0 \\
\rho_{5} \sigma_{11} & \rho_{8} \sigma_{11} & 0 & 0 & 0 & \sigma_{11}^{2} & \rho_{7} \sigma_{11} \sigma_{12} \\
\rho_{6} \sigma_{12} & \rho_{9} \sigma_{12} & 0 & 0 & 0 & \rho_{7} \sigma_{11} \sigma_{12} & \sigma_{12}^{2}
\end{array}\right)\right)
$$

Unfortunately, our attempts to estimate covariance matrices with less zero elements were unsuccessful. However, we should remark that specification (5) allows us to test for the presence of correlations between $V_{0}$, which is the residual of the main selection equation, and the other residuals (except $V_{l}$ ). Moreover, it also allows to test for the nullity of the coefficients of correlation between the residuals of the latent unemployment durations associated with transitions to permanent and to temporary jobs. These correlation coefficients correspond to the potential dependence of "competing risks" in the bivariate log-normal duration model. 
Identification of the model defined by equations (1)-(5) relies on an exclusion restriction: we assume that a plant closure affects the probability to join the program but that it does not influence the individual latent unemployment durations, essentially because it does not modify the parameters of the job search strategy (namely, the eligibility to UI benefits and the distribution of job wage offers). ${ }^{10}$ Let us recall that firms which laid off workers for economic reasons were required to participate to the funding of the retraining program. Obviously, plants which were closing faced much more difficulties to fund the program, which then might not be implemented. Indeed, results reported in Section 5 show that the probability to join the program is significantly lower for workers that were laid off because of a plant closing. ${ }^{11}$

Our first parameter of interest is the change in the probability to get a permanent job after program participation for a displaced worker with characteristics $X$ who actually join the program. ${ }^{12}$ This parameter is defined as :

$\Delta_{1}=\operatorname{Pr}\left(T_{1}=1, T_{2}=1 \mid X, T_{0}=1\right)+\operatorname{Pr}\left(T_{1}=0, Y_{11}<Y_{12} \mid X, T_{0}=1\right)-\operatorname{Pr}\left(Y_{01}<Y_{02} \mid X, T_{0}=1\right)$

The first term on the r.h.s. of this equation represents the probability for a participant with observable characteristics $X$ to move directly to a permanent job at the end of the program. ${ }^{13}$ The second term corresponds to the probability for the same participant to enter unemployment at the end of the program and to get a permanent job at the end of this unemployment spell (this second event occurs if the latent unemployment duration $Y_{11}$ associated with a transition to a permanent job is lower than latent the unemployment duration $Y_{12}$ associated with a transition to a temporary job). The last term is the probability for a participant to get a permanent job had he not participated in the program. This last event corresponds to the relevant counterfactual situation for a participant.

\footnotetext{
10 The argument put forward by Gibbons and Katz (1991) should not be valid in our context because all displaced workers that we consider were laid off for 'economic reasons' (because of redundancy). The lemons' argument can only be applied to workers fired for 'individual reasons', such as professional misconduct.

${ }^{11}$ Let us remark that it is not necessary to impose exclusion restrictions in equations (2) and (3), since a direct transition from the program to employment (especially to a permanent job) has no causal effect on latent unemployment durations.

${ }^{12}$ In our framework, this parameter corresponds to the "effect of the treatment on the treated".

${ }^{13}$ Vector $X$ includes all covariates introduced in the model defined by equations (1) to (4).
} 
We can also derive the variation of the probability to get a permanent job after program participation for a non-participant with characteristics $X$. This parameter, which corresponds to the "effect of the treatment on the non-treated", is given by :

$\Delta_{0}=\operatorname{Pr}\left(T_{1}=1, T_{2}=1 \mid X, T_{0}=0\right)+\operatorname{Pr}\left(T_{1}=0, Y_{11}<Y_{12} \mid X, T_{0}=0\right)-\operatorname{Pr}\left(Y_{01}<Y_{02} \mid X, T_{0}=0\right)$

Parameters of our model are estimated by the maximum likelihood technique. ${ }^{14}$ Analytical expressions of the contributions to the likelihood function are presented in Appendix 2.

\section{Results}

The parameter estimates of the model defined by equations (1) to (5) are reported in Table 1. First, we observe that the probability to join the program is lower:

- for blue-collar workers (skilled or not), more particularly for those who are not French citizens;

- more generally for workers previously belonging to a firm with more than 200 employees;

- for those who incurred collective layoffs with a plant closure ;

- and for those with tenure lower than 3 years in the previous firm.

Conversely, this probability is significantly higher for older workers (more than 50 years old) and managers. At this stage, the estimation does not reveal any difference between the three regions (Paris-Ile-de-France, Nord-Pas-de-Calais, and Provence-Alpes-Côte d'Azur).

Few variables have a significant impact on the probability for participants to move directly from the program to employment, especially to permanent employment. The older participants (more than 50 years old) or with more than 10 years of tenure are more likely to enter unemployment at the end of the program. Among participants who have been directly hired at the end of the program, only those who live in the southern region (Provence-AlpesCôte d'Azur) are more likely to move directly to a permanent job.

Estimates of coefficients of covariates affecting latent unemployment durations are generally significant and take the expected signs. However, depending on whether the displaced workers actually participated in training or not, the regressors influence the unemployment

\footnotetext{
${ }^{14}$ Maximum likelihood procedures were run with the Gauss 4.0 software.
} 
log-duration differently. Thus, female non-participants have a lower transition rate from unemployment to permanent employment than male non-participants. The situation is analogous for their transition rate from unemployment to temporary jobs.

However, the gap between women and men decreases with participation in the program. For instance, if we consider the latent unemployment duration associated with a transition to a permanent job without participation in the program, the coefficient of the covariate "woman" is equal to 0.90 , while it is equal to 0.45 after participation. We observe the same phenomenon when we compare the situation of educated to non-educated people or young people (less than 25 years old) to individuals between 25 and 40 years old. While less educated non-participants have a lower transition rate from unemployment to permanent employment, their transition rate to permanent jobs would be non significantly different had they participated in the program. However older participants (more than 40 years old) experience longer unemployment spells. Program participation has also differentiated effects between regions. Thus, if they do not join the program, displaced workers living in the northern region (Nord-Pas-de-Calais) experience longer unemployment spells before obtaining a permanent job. In fact, if they join the program, their mean unemployment logduration becomes analogous to the mean unemployment log-duration of displaced workers living in the region of Paris-Ile-de-France, where the local labour market is more dynamic. This effect is higher for displaced workers living in the southern region (Provence-Alpes-Côte d'Azur). Thus it would be worth examining the role of local institutions who are in charge of providing individual support to participants, in order to explain regional differences. How can we explain these equalizing effects of the program on unemployment durations? For instance, we may infer that participation improves significantly the position of low-skilled workers by increasing both their number of job offers and interviews. This hypothesis could be tested by the estimation of a structural model, such as a job search model.

We observe also that the variance of the unemployment log-duration is lower after participation. Therefore participation equalizes unemployment durations. The correlation coefficient between the residual of the program participation equation and the residual of the permanent job equation is negative and its absolute value is high (-0.9). The selection at entry into the program improves the situation of those who, ceteris paribus, are less likely to find directly a permanent job at the end of the program. 
Table 1 (beginning)

Estimated parameters of the simultaneous equations model

\begin{tabular}{|c|c|c|c|c|c|}
\hline Variables & Parameter & T - ratio & Variables & Parameter & $\mathrm{T}-$ ratio \\
\hline \multicolumn{3}{|c|}{ Program Participation (vector $\theta_{0}$ ) } & \multicolumn{3}{|c|}{ Direct transition to a permanent (vs. temporary) job (end) } \\
\hline Intercept & -0.9865 & $7.712 * * *$ & Nord-Pas-de-Calais region & -0.1667 & $1.294 \mathrm{~ns}$ \\
\hline Layoff without plant closure & 0.2026 & $3.362 * * *$ & Provence - Alpes Côte d'Azur region & 0.3144 & $2.270 *$ \\
\hline Woman & -0.0346 & $0.465 \mathrm{~ns}$ & \multicolumn{3}{|c|}{$\begin{array}{l}\text { Latent unemployment duration associated with a transition to a permanent job, } \\
\left.\text { for non-participants (vector } \beta_{01}\right)\end{array}$} \\
\hline Less than 25 years old & 0.0574 & $0.419 \mathrm{~ns}$ & Intercept & 4.0886 & $9.281 * * *$ \\
\hline Between 40 and 49 years old & 0.1049 & $1.486 \mathrm{~ns}$ & Woman & 0.9038 & $3.931 * * *$ \\
\hline More than 50 years old & 0.2203 & $2.290 *$ & Less than 25 years old & -0.7096 & $1.828 *$ \\
\hline Non French citizen & -0.1736 & $2.164 *$ & Between 40 and 49 years old & 0.0864 & $0.331 \mathrm{~ns}$ \\
\hline Skilled blue-collar worker & 0.1569 & $1.648 \mathrm{~ns}$ & More than 50 years old & 0.3512 & $1.031 \mathrm{~ns}$ \\
\hline White-collar worker & 0.2386 & $2.554^{* *}$ & Non French citizen & 0.3468 & $1.364 \mathrm{~ns}$ \\
\hline High-skilled worker & 0.2755 & $2.677^{* *}$ & Male, single & 0.5613 & $1.500 \mathrm{~ns}$ \\
\hline Manager & 0.4765 & $3.683 * * *$ & Technical school & -0.5621 & $2.345 *$ \\
\hline Tenure between 3 and 5 years & 0.8465 & $8.621^{* * *}$ & College education & -0.8256 & $1.961 *$ \\
\hline Tenure between 5 and 10 years & 0.9104 & $9.372 * * *$ & University degree & -0.6474 & $1.910 *$ \\
\hline Tenure higher than 10 years & 0.8763 & $8.611 * * *$ & Nord - Pas-de-Calais region & 0.8287 & $3.078 * * *$ \\
\hline Firm with more than 200 employees & -0.2719 & $3.493 * * *$ & Provence - Alpes Côte d'Azur region & 0.4550 & $1.847 *$ \\
\hline No response on firm size & -0.3728 & $2.203 *$ & \multicolumn{3}{|c|}{$\begin{array}{l}\text { Latent unemployment duration associated with a transition to a temporary job, } \\
\left.\text { for non-participants (vector } \beta_{02}\right)\end{array}$} \\
\hline Nord-Pas-de-Calais region & 0.1087 & $1.405 \mathrm{~ns}$ & Intercept & 3.7300 & $10.473 * * *$ \\
\hline Provence - Alpes Côte d'Azur region & -0.0489 & $0.669 \mathrm{~ns}$ & Woman & 0.4945 & $2.568^{* *}$ \\
\hline \multicolumn{3}{|c|}{ Direct transition from program to employment vs. unemployment (vector $\theta_{1}$ ) } & Less than 25 years old & -0.6531 & $2.083 *$ \\
\hline Intercept & 0.2182 & $0.818 \mathrm{~ns}$ & Between 40 and 49 years old & -0.0492 & $0.235 \mathrm{~ns}$ \\
\hline Woman & -0.1000 & $0.810 \mathrm{~ns}$ & More than 50 years old & 0.4654 & $1.512 \mathrm{~ns}$ \\
\hline Less than 25 years old & 0.2701 & $1.286 \mathrm{~ns}$ & Non French citizen & 0.4852 & $2.116 *$ \\
\hline Between 40 and 49 years old & -0.2101 & $1.777 \mathrm{~ns}$ & Male, single & -0.2759 & $1.000 \mathrm{~ns}$ \\
\hline More than 50 years old & -0.6769 & $3.986 * * *$ & Technical school & -0.3195 & $1.586 \mathrm{~ns}$ \\
\hline Non French citizen & -0.2138 & $1.361 \mathrm{~ns}$ & College education & -0.4086 & $1.124 \mathrm{~ns}$ \\
\hline Skilled blue-collar worker & 0.1016 & $0.630 \mathrm{~ns}$ & University degree & -0.3305 & $1.124 \mathrm{~ns}$ \\
\hline White-collar worker & -0.0455 & $0.274 \mathrm{~ns}$ & Nord - Pas-de-Calais region & -0.0289 & $0.144 \mathrm{~ns}$ \\
\hline High-skilled worker & 0.0621 & $0.358 \mathrm{~ns}$ & Provence - Alpes Côte d'Azur region & 0.3778 & $1.788 \mathrm{~ns}$ \\
\hline Manager & -0.0203 & $0.095 \mathrm{~ns}$ & \multicolumn{3}{|c|}{$\begin{array}{l}\text { Latent unemployment duration associated with a transition to a permanent job, } \\
\left.\text { for participants (vector } \beta_{11}\right)\end{array}$} \\
\hline Tenure between 3 and 5 years & -0.2867 & $1.274 \mathrm{~ns}$ & Intercept & 2.2313 & $5.643 * * *$ \\
\hline Tenure between 5 and 10 years & -0.3944 & $1.759 \mathrm{~ns}$ & Woman & 0.4477 & $1.978 *$ \\
\hline Tenure higher than 10 years & -0.5264 & $2.272 *$ & Less than 25 years old & -0.1749 & $0.378 \mathrm{~ns}$ \\
\hline Nord - Pas-de-Calais region & 0.1261 & $0.966 \mathrm{~ns}$ & Between 40 and 49 years old & 0.4643 & $3.136 * * *$ \\
\hline Provence - Alpes Côte d'Azur region & 0.0435 & $0.337 \mathrm{~ns}$ & More than 50 years old & 1.0976 & $5.861 * * *$ \\
\hline \multicolumn{3}{|c|}{ Direct transition to a permanent (vs. temporary) job (vector $\left.\theta_{2}\right)$} & Non French citizen & 0.2123 & $1.152 \mathrm{~ns}$ \\
\hline Intercept & Single man & $2.512^{* *}$ & Male, single & 0.5134 & $1.947 *$ \\
\hline Woman & -0.0110 & $0.082 \mathrm{~ns}$ & Technical school & -0.1244 & $0.628 \mathrm{~ns}$ \\
\hline Less than 25 years old & 0.2865 & $1.435 \mathrm{~ns}$ & College education & 0.2109 & $0.773 \mathrm{~ns}$ \\
\hline Between 40 and 49 years old & -0.0688 & $0.564 \mathrm{~ns}$ & University degree & -0.4445 & $1.625 \mathrm{~ns}$ \\
\hline More than 50 years old & -0.0304 & $0.135 \mathrm{~ns}$ & Nord - Pas-de-Calais region & 0.1145 & $0.460 \mathrm{~ns}$ \\
\hline Non French citizen & 0.1975 & $1.232 \mathrm{~ns}$ & Provence - Alpes Côte d'Azur region & -0.4326 & $2.776 * *$ \\
\hline Skilled blue-collar worker & -0.0045 & $0.028 \mathrm{~ns}$ & & & \\
\hline White-collar worker & 0.1286 & $0.726 \mathrm{~ns}$ & & & \\
\hline High-skilled worker & -0.0722 & $0.398 \mathrm{~ns}$ & & & \\
\hline Manager & 0.0682 & $0.297 \mathrm{~ns}$ & & & \\
\hline
\end{tabular}


Table 1 (end)

\begin{tabular}{|c|c|c|c|c|c|}
\hline Variables & Parameter & $\mathrm{T}-$ ratio & Variables & Parameter & $\mathrm{T}-$ ratio \\
\hline \multicolumn{3}{|c|}{$\begin{array}{l}\text { Latent unemployment duration associated with a transition to a temporary job, } \\
\left.\text { for participants (vector } \beta_{12}\right)\end{array}$} & \multicolumn{3}{|c|}{ Covariance matrix } \\
\hline Intercept & 2.3009 & $3.253 * * *$ & $\sigma_{01}$ & 2.0805 & $11.821 * * *$ \\
\hline Woman & 0.3614 & $1.364 \mathrm{~ns}$ & $\sigma_{02}$ & 1.8684 & $15.969^{* * *}$ \\
\hline Less than 25 years old & -0.2827 & $0.773 \mathrm{~ns}$ & $\sigma_{11}$ & 1.3998 & $14.430 * * *$ \\
\hline Between 40 and 49 years old & 0.4589 & $3.146^{* * *}$ & $\sigma_{I 2}$ & 1.3893 & $16.154^{* * *}$ \\
\hline More than 50 years old & 1.1145 & $5.846 * * *$ & $\rho_{l}$ & -0.9010 & $18.771^{* * *}$ \\
\hline Non French citizen & 0.2326 & $1.254 \mathrm{~ns}$ & $\rho_{2}$ & 0.0191 & $0.087 \mathrm{~ns}$ \\
\hline Male, single & 0.5242 & $1.954 *$ & $\rho_{3}$ & -0.0445 & $0.224 \mathrm{~ns}$ \\
\hline Technical school & -0.1809 & $0.918 \mathrm{~ns}$ & $\rho_{4}$ & -0.7840 & $5.560 * * *$ \\
\hline College education & 0.2246 & $0.814 \mathrm{~ns}$ & $\rho_{5}$ & 0.4243 & $3.689 * * *$ \\
\hline University degree & -0.3106 & $0.655 \mathrm{~ns}$ & $\rho_{6}$ & 0.4308 & $3.989 * * *$ \\
\hline Nord-Pas-de-Calais region & 0.0376 & $0.156 \mathrm{~ns}$ & $\rho_{7}$ & 0.9844 & $6.434 * * *$ \\
\hline \multirow[t]{2}{*}{ Provence - Alpes Côte d'Azur region } & -0.4124 & $2.439 * *$ & $\rho_{8}$ & 0.1534 & $4.32 \cdot 10^{-6} \mathrm{~ns}$ \\
\hline & & & $\rho_{9}$ & -0.0027 & 1.06. $10-5 \mathrm{~ns}$ \\
\hline \multicolumn{3}{|c|}{ Number of observations : 1,912} & & $:-4341.88$ & \\
\hline
\end{tabular}

Source : Surveys on "Trajectories of the Unemployed and Local Labor Market" and "Trajectories of Participants of a Convention of Conversion" (French Ministry of Labour).

Significance levels : *** $(0.1 \%), * *(1 \%), *(5 \%)$ and ns (non significant at the $5 \%$ level).

Program participants have no unobservable characteristics which can prone them to experience longer (or smaller) unemployment duration, had they not joined the program $\left(\rho_{2}\right.$ and $\rho_{3}$ are not significantly different from zero). Conversely, participants have unobservable characteristics that reduce, ceteris paribus, their subsequent average unemployment duration ( $\rho_{5}$ and $\rho_{6}$ are positive and significantly different from zero). Consequently, selections affecting program participation involve several types of unobserved criteria; these selections go in opposite directions and make a global interpretation difficult. Furthermore, we observe that without participation, the residual of the latent unemployment duration associated with a transition to a permanent job is negatively correlated with the residual of the latent unemployment duration associated with a transition to a temporary job ( $\rho_{4}$ is significantly negative): in the absence of program participation, displaced workers who move less frequently (or less rapidly) from unemployment to permanent employment are those who obtain more often (or more rapidly) temporary jobs. The sign of the correlation is modified by program participation: the residuals of the latent unemployment durations associated with a transition to a permanent job and with a transition to a temporary job are positively correlated. This implies that a participant who enters unemployment after the program is, other observable things being equal, equally employable either in a permanent or in a temporary job ( $\rho_{7}$ is equal to 0.98 ). This last result has to be associated with the fact that correlation coefficients $\rho_{5}$ and $\rho_{6}$ are positive and equal. Finally, correlation coefficients $\rho_{8}$ and $\rho_{9}$ are not 
statistically different from zero: the error term affecting the probability of a direct transition to employment at the end of the program is stochastically independent of the error terms affecting the latent unemployment durations associated with transitions to permanent or temporary jobs for program participants.

Lastly, using equations (6) and (7), we estimate the variation of the probability to get a permanent job after program participation for different groups of displaced workers, whether they actually join the program or not (see Table 2). For non-participants, the program would have increased their probability to obtain a permanent job by 28 points. But the increase is much lower for participants (8 points only).

Table 2

Estimated probabilities to move to a permanent job after program participation

\begin{tabular}{|c|c|c|c|c|c|c|}
\hline & \multicolumn{3}{|c|}{ For non-participants } & \multicolumn{3}{|c|}{ For participants } \\
\hline & Program & No program & Difference & Program & No program & Difference \\
\hline On average & 0.70 & 0.43 & 0.27 & 0.51 & 0.41 & 0.10 \\
\hline Men & 0.64 & 0.42 & 0.22 & 0.47 & 0.40 & 0.07 \\
\hline Women & 0.74 & 0.44 & 0.30 & 0.53 & 0.43 & 0.10 \\
\hline Less than 25 years old & 0.69 & 0.43 & 0.26 & 0.51 & 0.42 & 0.09 \\
\hline Between 26 and 39 years old & 0.68 & 0.43 & 0.25 & 0.51 & 0.41 & 0.10 \\
\hline Between 40 and 49 years old & 0.70 & 0.44 & 0.26 & 0.51 & 0.42 & 0.09 \\
\hline More than 50 years old & 0.70 & 0.43 & 0.27 & 0.50 & 0.41 & 0.09 \\
\hline $1^{\text {st }}$ stage of secondary education & 0.67 & 0.41 & 0.26 & 0.48 & 0.38 & 0.10 \\
\hline $2^{\text {nd }}$ stage of secondary education & 0.70 & 0.42 & 0.28 & 0.51 & 0.40 & 0.11 \\
\hline Technical school & 0.66 & 0.44 & 0.22 & 0.45 & 0.42 & 0.03 \\
\hline College degree & 0.72 & 0.46 & 0.26 & 0.53 & 0.44 & 0.09 \\
\hline University degree & 0.83 & 0.46 & 0.37 & 0.63 & 0.43 & 0.20 \\
\hline Layoff without plant closure & 0.69 & 0.43 & 0.26 & 0.51 & 0.41 & 0.10 \\
\hline Layoff with plant closure & 0.68 & 0.43 & 0.25 & 0.49 & 0.41 & 0.08 \\
\hline Blue-collar workers & 0.69 & 0.43 & 0.26 & 0.47 & 0.41 & 0.06 \\
\hline White-collar workers & 0.66 & 0.43 & 0.23 & 0.50 & 0.41 & 0.09 \\
\hline High-skilled workers & 0.73 & 0.45 & 0.28 & 0.53 & 0.43 & 0.10 \\
\hline Managers & 0.80 & 0.47 & 0.33 & 0.63 & 0.45 & 0.18 \\
\hline Tenure between 2 and 3 years & 0.73 & 0.43 & 0.30 & 0.36 & 0.40 & -0.04 \\
\hline Tenure between 3 and 5 years & 0.72 & 0.44 & 0.28 & 0.51 & 0.42 & 0.09 \\
\hline Tenure between 5 and 10 years & 0.69 & 0.43 & 0.26 & 0.52 & 0.42 & 0.10 \\
\hline Tenure higher than 10 years & 0.65 & 0.43 & 0.22 & 0.51 & 0.41 & 0.10 \\
\hline
\end{tabular}

A complementary analysis (see Table 2) shows that among non-participants, the groups which are more likely to benefit the most from program participation are the most educated individuals (their average probability to obtain a permanent contract increases by 37 points), the highest-skilled workers (for managers, the difference increases by 33 points), the workers with low tenure (for tenures lower than three years, the difference increases by 30 points) and women (the increase is also by 30 points). Among participants, individuals who would have 
benefited the most from participation are the most educated workers (the difference increases by 20 points), the highest-skilled workers (for managers, the difference increases by 18 points; for high-skilled workers, it increases by 10 points) and women (increase by 10 points).

Thus, in both groups, non-participants and participants, categories which benefit the most from the program participation are roughly the same. However, we may remark that for these individuals, the probabilities to obtain a permanent job without joining the program are analogous (roughly 45\%). How can we explain that participation affects more the probability to find a permanent job for non-participants? A simple descriptive analysis shows that the observable characteristics of these two categories are different. Particularly, high-educated and high-skilled non-participants present characteristics which are likely to increase the transition rate to permanent job more frequently than the comparable participants. For instance, among highly educated non-participants, 55\% are less than 35 years old, while this proportion represents $43 \%$ among participants. In a nutshell, individuals with a higher employability level are more numerous among non-participants than among participants.

\section{Concluding remarks}

The aim of this article was to estimate the impact of a retraining program targeted to displaced workers on their return to permanent employment. The model used for evaluating this impact is a Tobit model with multiple selection criteria. This model allows us to take into account not only the selection at entry into the program, but also the endogenous selection occurring when participants move directly from the program to a permanent job. More generally, the treatment effect of the program on transitions from unemployment to permanent vs. temporary jobs is estimated using a dependent competing risks duration model.

The results show that the probability to join the retraining program is higher for displaced workers who incurred mass layoff without plant's closure. It increases with skill level and seniority in the previous firm. On average, program participation increases the probability to get a permanent job by 8 points for participants. However, program participation would have increased this probability by 28 points for non-participants. Categories which benefit the most from the program are high-skilled and high-educated displaced workers. 
These results suggest that the program might not have been offered primarily to individuals who would have benefited the most from it. It has been more frequently offered to older workers who face very low probabilities of reemployment in France, ${ }^{15}$ while it should have been also offered to skilled adult workers.

Finally, we should remark that our application relies on a standard parametric assumption concerning the joint distribution of random terms. A possible extension of this study should be to evaluate the impact of the program using a semi-parametric selection model, following the procedure proposed by Das, Newey and Vella (2003).

\section{Acknowledgements}

We thank Laurent Gobillon, Peter Jensen, Thierry Kamionka, David Leblanc, David Margolis, and Michael Rosholm for their remarks and suggestions. Participants of seminars and conferences in Aarhus, ESEM 2004 in Madrid, Paris, and Rennes, provided helpful comments. The usual disclaimer applies.

\footnotetext{
${ }^{15}$ The estimate of the coefficient associated with the dummy indicator "more than 50 years old" is the sole coefficient which is statistically significant among coefficients associated with age dummies in the participation equation (see Table 1).
} 


\section{Appendix 1}

\section{Table 3}

Descriptive statistics for both sub-samples, participants and non-participants (percentages)

\begin{tabular}{|c|c|c|}
\hline Socio-demographic characteristics & Non - participants & Participants \\
\hline Between 16 and 25 years old & 7.87 & 6.24 \\
\hline Between 26 and 39 years old & 50.44 & 45.74 \\
\hline Between 40 and 49 years old & 30.49 & 33.56 \\
\hline More than 50 years old & 11.20 & 14.46 \\
\hline Women & 54.10 & 55.84 \\
\hline French citizenship & 77.94 & 84.95 \\
\hline Widowed & 8.65 & 9.71 \\
\hline Married & 72.62 & 76.73 \\
\hline Single & 18.74 & 14.16 \\
\hline Paris-Ile-de-France region & 35.37 & 33.07 \\
\hline Nord-Pas-de-Calais region & 28.16 & 33.27 \\
\hline Provence-Alpes-Côte d'Azur region & 36.47 & 33.66 \\
\hline \multicolumn{3}{|l|}{ Educational level } \\
\hline Primary education & 12.64 & 12.87 \\
\hline $1^{\text {st }}$ stage of secondary education level & 12.97 & 10.30 \\
\hline $2^{\text {nd }}$ stage of secondary education level & 9.09 & 7.72 \\
\hline Technical school & 40.58 & 40.10 \\
\hline College education & 7.10 & 8.61 \\
\hline University degree & 13.30 & 18.02 \\
\hline \multicolumn{3}{|l|}{ Tenure in the previous job (years) } \\
\hline Between 2 and 3 years & 21.62 & 5.94 \\
\hline Between 3 and 5 years & 23,50 & 30.30 \\
\hline Between 5 and 10 years & 24.06 & 33.17 \\
\hline More than 10 more[ & 25.83 & 30.59 \\
\hline \multicolumn{3}{|l|}{ Skill level in the last job } \\
\hline Unskilled blue-collar worker & 23.95 & 17.43 \\
\hline Skilled blue-collar worker & 22.06 & 22.18 \\
\hline White-collar worker & 32.04 & 32.87 \\
\hline High-skilled worker & 14.86 & 17.62 \\
\hline Manager & 6.32 & 9.70 \\
\hline \multicolumn{3}{|l|}{ Transitions and unemployment duration } \\
\hline Right-censored unemployment spells & 51.00 & 36.73 \\
\hline Transitions to permanent jobs & 18.40 & 31.58 \\
\hline Transitions to temporary jobs & 26.17 & 31.69 \\
\hline Mean unemployment duration (in months) & 13 & 9 \\
\hline Number of observations & 902 & 1010 \\
\hline
\end{tabular}




\section{Appendix 2. Contributions to the likelihood function}

a) For a displaced worker who joins the program and then moves directly to a permanent job:

$$
\operatorname{Pr}\left[V_{0}>-Z_{0} \theta_{0}, \quad V_{1}>-Z_{1} \theta_{1}, \quad V_{2}>-Z_{2} \theta_{2}\right]
$$

b) For a displaced worker who joins the program and then moves directly to a temporary job:

$$
\operatorname{Pr}\left[V_{0}>-Z_{0} \theta_{0}, \quad V_{1}>-Z_{1} \theta_{1}, \quad V_{2}<-Z_{2} \theta_{2}\right]
$$

c) For a displaced worker who joins the program, then enters unemployment and finally gets a permanent job after $y_{11}=T$ months in unemployment (with $\ln y_{11}=X_{11} \beta_{11}+u_{11}$ ):

$$
\begin{gathered}
\operatorname{Pr}\left[V_{0}>-Z_{0} \theta_{0}, \quad V_{1}<-Z_{1} \theta_{1}, \quad U_{11}=u_{11}, U_{12}>\ln T-X_{12} \beta_{12}\right] \\
=\frac{1}{\sigma_{11}} \varphi\left(\frac{u_{11}}{\sigma_{11}}\right) \cdot \operatorname{Pr}\left[V_{0}>-Z_{0} \theta_{0}, \quad V_{1}<-Z_{1} \theta_{1}, \quad U_{12}>\ln T-X_{12} \beta_{12} \mid U_{11}=u_{11}\right]
\end{gathered}
$$

d) For a displaced worker who joins the program, then enters unemployment and finally gets a temporary job after $y_{12}=T$ months in unemployment (with $\ln y_{12}=X_{12} \beta_{12}+u_{12}$ ):

$$
\begin{gathered}
\operatorname{Pr}\left[V_{0}>-Z_{0} \theta_{0}, \quad V_{1}<-Z_{1} \theta_{1}, \quad U_{11}>\ln T-X_{11} \beta_{11}, U_{12}=u_{12}\right] \\
=\frac{1}{\sigma_{12}} \varphi\left(\frac{u_{12}}{\sigma_{12}}\right) \operatorname{Pr}\left[V_{0}>-Z_{0} \theta_{0}, \quad V_{1}<-Z_{1} \theta_{1}, \quad U_{11}>\ln T-X_{11} \beta_{11} \mid U_{12}=u_{12}\right]
\end{gathered}
$$

e) For a displaced worker who joins the program, then enters unemployment and is still unemployed at the end of the observation period (the unemployment spell is right-censored after $T$ months):

$$
\operatorname{Pr}\left[V_{0}>-Z_{0} \theta_{0}, \quad V_{1}<-Z_{1} \theta_{1}, \quad U_{11}>\ln T-X_{11} \beta_{11}, \quad U_{12}>\ln T-X_{12} \beta_{12}\right]
$$

f) For a displaced worker who does not join the program, enters unemployment and gets a permanent job after $y_{01}=T$ months in unemployment (with $\left.\ln y_{01}=X_{01} \beta_{01}+u_{01}\right)$ : 


$$
\begin{gathered}
\operatorname{Pr}\left[V_{0}<-Z_{0} \theta_{0}, \quad U_{01}=u_{01}, \quad U_{02}>\ln T-X_{02} \beta_{02}\right] \\
=\frac{1}{\sigma_{01}} \varphi\left(\frac{u_{01}}{\sigma_{01}}\right) \operatorname{Pr}\left[V_{0}<-Z_{0} \theta_{0}, \quad U_{02}>\ln T-X_{02} \beta_{02} \mid U_{01}=u_{01}\right]
\end{gathered}
$$

g) For a displaced worker who does not join the program, enters unemployment and gets a temporary job after $y_{02}=T$ months in unemployment (with $\ln y_{02}=X_{02} \beta_{02}+u_{02}$ ):

$$
\begin{gathered}
\operatorname{Pr}\left[V_{0}<-Z_{0} \theta_{0}, \quad U_{01}>\ln T-X_{01} \beta_{01}, U_{02}=u_{02}\right] \\
=\frac{1}{\sigma_{02}} \varphi\left(\frac{u_{02}}{\sigma_{02}}\right) \operatorname{Pr}\left[V_{0}<-Z_{0} \theta_{0}, \quad U_{01}>\ln T-X_{01} \beta_{01} \mid U_{02}=u_{02}\right]
\end{gathered}
$$

h) For a displaced worker who does not join the program, enters unemployment and is still unemployed at the end of the observation period (the unemployment spell is right-censored after $T$ months):

$$
\operatorname{Pr}\left[V_{0}<-Z_{0} \theta_{0}, \quad U_{01}>\ln T-X_{01} \beta_{01}, \quad U_{02}>\ln T-X_{02} \beta_{02}\right]
$$

In order for $\Sigma$ to be a positive definite matrix (see equation 5), we use the Choleski decomposition $\Sigma=L L^{\prime}$. The standard deviations of estimated covariances are estimated through the delta method. Thus they are given by:

$$
\hat{\mathrm{V}}(\hat{\Sigma})=\left[\frac{\partial \Sigma}{\partial \mathrm{L}}\right]_{\mathrm{L}=\hat{\mathrm{L}}} \times \hat{\mathrm{V}}(\hat{\mathrm{L}}) \times\left[\frac{\partial \Sigma}{\partial \mathrm{L}}\right]_{\mathrm{L}=\hat{\mathrm{L}}}^{\prime}
$$

where $\hat{V}(\hat{L})$ is the covariance matrix estimated as a function of the lower triangular matrix $L$ of the Choleski decomposition of $\Sigma$, and $\left\lfloor\frac{\partial \Sigma}{\partial L}\right\rfloor_{L=\hat{L}}$ is the Jacobian matrix evaluated at $L=\hat{L}$. 


\section{References}

Addison, J. T., Portugal, P., 1989. Job displacement, relative wage changes and duration of unemployment. Journal of Labor Economics 7, 281-302.

Bonnal, L., Fougère, D., Sérandon, A., 1997. Evaluating the impact of French employment policies on individual labor market histories. The Review of Economic Studies 64, 683-713.

Brodaty, T., Crépon, B., Fougère, D., 2001. Using kernel matching estimators to evaluate alternative youth employment programs: evidence from France, 1986-1988. In: Lechner, M., Pfeiffer, F. (Eds.), Econometric Evaluations of Labour Market Policies. Physica Verlag, Heidelberg, 85-124.

Brodaty, T., Crépon, B., Fougère, D. ,2002. Do long-term unemployed workers benefit from active labor market programs?. Working Paper, CREST-INSEE, Paris.

Dar, A., Gill, I., 1998. Evaluating retraining programs in OECD countries : lessons learned. World Bank Research Observer 13, 79-101.

Das, M., Newey, W., Vella, F., 2003. Nonparametric estimation of sample selection models. The Review of Economic Studies 70, 33-58.

Fallick, B.C., 1996. A review of the recent empirical literature on displaced workers. Industrial and Labor Relations Review 50, 5-16.

Farber, H.S., 1999. Alternative and part-time employment arrangements as a response to job loss. Journal of Labor Economics 17, S142-S169.

Farber, H.S., 2003. Job loss in the United States, 1981-2001. Working Paper no 471, Princeton University.

Florens, J.P., Fougère, D., Mouchart, M., 1996. Duration models. In: Matyas, L., Sevestre, P. (Eds.), The Econometrics of Panel Data (Second Edition). Kluwer Academic Press, Dordrecht, 491-536.

Fougère, D., Kramarz, F., Magnac, T., 2000. Youth employment policies in France. European Economic Review 44, 928-942.

Gibbons, R., Katz, L., 1991. Layoffs and lemons. Journal of Labor Economics 9, 299-318.

Heckman, J. J., Lalonde, R. J., Smith, J. A., 2000. The economics and econometrics of active labor market programs. In: Ashenfelter, O., Card, D. (Eds.), Handbook of Labor Economics, Vol. 3A. North Holland, Amsterdam, 1865-2097.

Jacobson L., Lalonde, R.J., Sullivan, D.J., 1993. Earnings losses of displaced workers. American Economic Review 83, 685-709.

Kletzer, L., 1998. Job displacement. Journal of Economic Perspectives 12, 115-136. 
Lalive, R., Van Ours, J.C., Zweimüller, J., 2000. The impact of active labor market programs and benefit entitlement rules on the duration of employment. Discussion Paper no 149, IZA, Bonn.

Lancaster, T., 1990. The econometric analysis of transition data. Econometric Society Monographs, Cambridge University Press, New-York.

Leigh, D. E., 1990. Does training work for displaced workers? A study of existing evidence. W.E Upjohn Institute, Kalamazoo, Michigan.

Maddala, G. S., 1983. Limited-dependent and qualitative variables in econometrics. Econometric Society Monographs, Cambridge University Press, New-York.

Margolis, D.,1999. Part-year employment, slow reemployment and earnings losses: the case of worker displacement in France. In: Haltiwanger, J. C., Lane, J. L., Spletzer, J. R., Theeuwes, J. J. M., Troske, K. R. (Eds.), The Creation and Analysis of Employer-Employee Matched Data. North-Holland, Amsterdam, 375-416.

Moore, T., 1990. The nature and unequal incidence of job displacement costs. Social Problems 37, 230-242.

OECD, 1994. The OECD jobs study: evidence and explanations. OECD, Paris.

OECD, 1996. The OECD jobs study : enhancing the effectiveness of active labor market policies. OECD, Paris.

Ruhm, C. J., 1991. Are workers permanently scarred by job displacement? American Economic Review 81, 319-323.

Stock, W., 1998. Predicting displaced worker industry-switching: targeting training programs. Growth \& Change 29, 3-22.

Swaim, P., Podgursky, M., 1991. The distribution of economic losses among displaced workers: a replication. Journal of Human Resources 26, 742-755. 